\title{
Development of diagnostic PCR and LAMP markers for MALE STERILITY 1 (MS1) in Cryptomeria japonica D. Don
}

\author{
Yoichi Hasegawa ${ }^{10}$, Saneyoshi Ueno ${ }^{1 *}$, Fu-Jin Wei ${ }^{1}$, Asako Matsumoto ${ }^{1}$, Tokuko Ujino-Ihara', \\ Kentaro Uchiyama ${ }^{1}$, Yoshinari Moriguchi ${ }^{2}$, Masahiro Kasahara ${ }^{3}$, Takeshi Fujino ${ }^{3}$, Shuji Shigenobu ${ }^{4}$, \\ Katsushi Yamaguchi ${ }^{4}$, Takahiro Bino ${ }^{4}$ and Tetsuji Hakamata ${ }^{5}$
}

\begin{abstract}
Objective: Due to the allergic nature of the pollen of Cryptomeria japonica, the most important Japanese forestry conifer, a pollen-free cultivar is preferred. Mutant trees detected in nature have been used to produce a pollen-free cultivar. In order to reduce the time and cost needed for production and breeding, we aimed to develop simple diagnostic molecular markers for mutant alleles of the causative gene MALE STERILITY 1 (MS1) in C. japonica to rapidly identify pollen-free mutants.

Results: We developed PCR and LAMP markers to detect mutant alleles and to present experimental options depending on available laboratory equipment. LAMP markers were developed for field stations, where PCR machines are unavailable. The LAMP method only needs heat-blocks or a water bath to perform the isothermal amplification and assay results can be read by the naked eye. Because the causative mutations were deletions, we developed two kinds of PCR markers, amplified length polymorphism (ALP) and allele specific PCR (ASP) markers. These assays can be visualized using capillary or agarose gel electrophoresis.
\end{abstract}

Keywords: ALP, ASP, LAMP, Molecular markers, Variant detection, Cryptomeria japonica, Sugi

\section{Introduction}

Molecular markers allow for the selection of specific phenotypes, once the genetic linkage of markers with associated genotypes and candidate gene(s) are identified. Due to the large body mass of tree species, especially conifers, maker-assisted selection with a candidate gene at the early life stage (e.g., seedling) is helpful in reducing the cost and time of breeding. Sugi (Cryptomeria japonica D. Don) is the most important forestry conifer in Japan, it occupies about $40 \%$ of artificial forests. Due to its fast growth and straight bowl, sugi timber has

\footnotetext{
*Correspondence: saueno@ffpri.affrc.go.jp

${ }^{1}$ Forestry and Forest Products Research Institute, Forest Research

and Management Organization, Tsukuba, Ibaraki, Japan

Full list of author information is available at the end of the article
}

been used for building materials and for daily life consumables, such as chopsticks and bowls. Recently, however, the pollen of sugi has caused seasonal allergies, which affects approximately $25 \%$ of Japanese citizens [1]. Therefore, breeding efforts are currently focused on producing a sterile pollen cultivar [2]. A candidate gene for male sterility, MALE STERILITY 1 (MS1), has been identified by transcriptome analysis and linkage mapping [3-5]. Sequencing analysis of the gene (C)t020762: 2,479 bp) from 83 samples identified 49 haplotypes with observed $\left(H_{\mathrm{O}}\right)$ and expected $\left(H_{\mathrm{E}}\right)$ heterozygosity of 0.892 and 0.920 , respectively (Additional file 1 ), along with the two deletion mutations, both of which were expected to result in the mutant alleles which cause sterility (ms1-1 and $m s 1-2$ of the haplotype 38 and 4 , respectively) [4]. Diagnostic molecular markers are useful for work both in

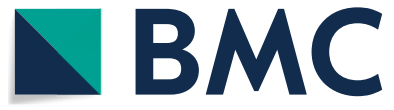

(c) The Author(s) 2020. This article is licensed under a Creative Commons Attribution 4.0 International License, which permits use, sharing, adaptation, distribution and reproduction in any medium or format, as long as you give appropriate credit to the original author(s) and the source, provide a link to the Creative Commons licence, and indicate if changes were made. The images or other third party material in this article are included in the article's Creative Commons licence, unless indicated otherwise in a credit line to the material. If material is not included in the article's Creative Commons licence and your intended use is not permitted by statutory regulation or exceeds the permitted use, you will need to obtain permission directly from the copyright holder. To view a copy of this licence, visit http://creativeco mmons.org/licenses/by/4.0/. The Creative Commons Public Domain Dedication waiver (http://creativecommons.org/publicdomain/ zero/1.0/) applies to the data made available in this article, unless otherwise stated in a credit line to the data. 
laboratories and forest stations to search for the mutant alleles (ms1). Such markers would be useful in breeding efforts to produce pollen-free male sterile sugi.

Here, we developed diagnostic markers for MS1 in sugi for use in laboratories and forest stations. Amplicon length polymorphism (ALP) and allele specific PCR (ASP) markers were developed for laboratories equipped with capillary and/or gel electrophoretic systems. These markers are suitable for precise determination of genotypes. For work taking place in nurseries and forest stations, we also developed LAMP (loop-mediated isothermal amplification) [6] primer sets. LAMP experiments are less resource intensive and enable the rapid detection of alleles in the field without the need for a molecular biology laboratory. Using these markers in breeding projects for male sterility will boost the production of male sterile cultivars, while simultaneously reducing airborne pollen and mitigating citizens' allergies.

\section{Main text}

\section{Materials and methods}

Three individual trees with known genotypes for MS1: 'Fukushima1' (ms1-1/ms1-1), 'Ooi-7' (Ms1/ms1-2), and 'G492' (Ms1/ms1-1) were used from a mapping family of MS1 [5]. 'G492' is an offspring of the cross between 'Fukushima1' (male sterile seed parent) and 'Ooi-7' (male fertile pollen parent). Sequencing analysis was performed for the MS1 gene (CJt020762) for 'Fukushima1' and 'Ooi7', and it confirmed a 4-base pair (bp) deletion on the first exon and a 30-bp deletion on the third exon, respectively, for the $m s 1-1$ and $m s 1-2$ alleles [4]. An additional sample, 'Shindai3' (ms1-1/ms1-1), was also analyzed.

We applied the cetyltrimethylammonium bromide (CTAB) method, which is widely used to extract DNA from tree species. CTAB efficiently removes polysaccharides from tree tissue and recovers high-quality DNA [7]. In the current study, about $100 \mathrm{mg}$ of leaves, which were frozen with liquid nitrogen, were ground into fine powder with a TissueLyser II (Qiagen). The powder was washed by adding $0.9 \mathrm{~mL}$ of extraction buffer I (Additional file 2) and collected by centrifugation. The supernatant was discarded. This process was repeated if the supernatant was viscous. Then, $0.3 \mathrm{~mL}$ of wash buffer (Additional file 2) and $30 \mu \mathrm{L}$ of $10 \%$ sodium $\mathrm{N}$-dodecanoyl salcosinate were added. The mixture was left for $15 \mathrm{~min}$ at room temperature, before $0.3 \mathrm{~mL}$ of $2 \times$ CTAB buffer (Additional file 2) was added. The mixture was incubated for $10 \mathrm{~min}$. at $60{ }^{\circ} \mathrm{C}$. Then, $0.6 \mathrm{~mL}$ of chloroform-isoamylalchol (ch loroform:isoamylalchohol $=24: 1$ ) was added, the aqueous layer was collected by centrifugation, and the DNA was precipitated by adding $2 / 3$ volume of isopropanol. The precipitate was collected by centrifugation, washed by $70 \%$ ethanol, and dissolved into an appropriate volume
$(100 \mu \mathrm{L})$ of TE buffer. RNA molecules were digested by adding $1 \mu \mathrm{L}$ of RNase $(2 \mathrm{mg} / \mathrm{mL})$ and incubating for 2 $\mathrm{h}$ at $37{ }^{\circ} \mathrm{C}$. One micro-litter of DNA solution (around 10-50 ng DNA) was used for amplification.

Because the target mutations of MS1 gene (CJt020762, DNA Databank of Japan, DDBJ, accession numbers: LC536580 and LC538205) are deletions, we designed PCR primers to amplify products of differing length using Primer3 software $[8,9]$. PCR was performed in a 10 $\mu \mathrm{L}$ reaction containing $1 \mu \mathrm{L}$ of template DNA, $1 \times$ Multiplex PCR Master Mix (Qiagen), and $0.2 \mu \mathrm{M}$ of non-tailed primer, and $0.1 \mu \mathrm{M}$ of each of tail [10] and tailed primer (Table 1 and Additional file 3). The reaction was initially heat-denatured for $15 \mathrm{~min}$ at $95^{\circ} \mathrm{C}$, followed by 35 cycles of $94{ }^{\circ} \mathrm{C}$ for $30 \mathrm{~s}, 60^{\circ} \mathrm{C}$ for $90 \mathrm{~s}$, and $72{ }^{\circ} \mathrm{C}$ for $60 \mathrm{~s}$, with a final extension for $30 \mathrm{~min}$ at $60^{\circ} \mathrm{C}$, using a GeneAmp 9700 PCR System (Applied Biosystems). In addition, we synthesized specific primers to which fluorescent dye was directly attached and then carried out multiplex PCR (Additional file 3) using KAPA2G Fast PCR Kit (NIPPON Genetics). The PCR products were diluted appropriately (usually by 10 times) and run on a 3130 Genetic Analyzer (Applied Biosystems) with LIZ size standard (ThermoScientific).

For laboratories where capillary sequencers are not available, allele specific PCR (ASP) primers, whose products can be analyzed on agarose gels, were designed with Primer3 software [9]. One of the 3' ends of a primer was positioned on the mismatched site due to the deletion. In addition, an artificial mismatch was introduced at the third base from 3 ' end (antepenultimate position) of the primer to increase the difference in the melting temperature between matched and mismatched primertemplate pairs. This mismatch increased allelic specificity of the primer $[11,12]$. The antepenultimate position is, for the most part, effective to differentiate alleles. Moreover, either purine-purine or pyrimidine-pyrimidine mismatch types, which are expected to be more unstable than that of purine-pyrimidine mismatch, were selected. Multiplex PCR for MS1 and one of the eight microsatellite markers in C. japonica (Additional file 4) were tested, and the best pair was selected based on readability of the amplified bands on agarose gels. Because it is better to include a positive control reaction in PCR, we amplified a microsatellite marker as a positive control. As a result, at least one band was visible when the product was analyzed by electrophoresis. To mitigate non-specific amplification, primers that produce shorter PCR products (with the Primer3 option: "PRIMER_PRODUCT SIZE_RANGE $=100-250 "$ ) and shorter elongation time in PCR were selected. Reactions were carried out in 10 $\mu \mathrm{L}$ reaction containing $1 \mu \mathrm{L}$ of template DNA, $1 \times$ Multiplex PCR Master Mix (Qiagen), and $0.2 \mu \mathrm{M}$ of each of 
Table 1 Primer sequences for PCR and LAMP diagnostic marker sets of MS1 in Cryptomeria japonica

\begin{tabular}{|c|c|c|}
\hline Maker ID & Primer ID & Primer sequence $^{\mathbf{a}}$ \\
\hline \multirow[t]{2}{*}{ (a) ALP_ms1-1 } & CJt020762_F145 & CCATGCCTTTCTTACATGACGAG \\
\hline & CJt020762_R294_A & GCCTCCCTCGCGCCATTGATTAATGGGAAAGCCCAGAA \\
\hline \multirow[t]{2}{*}{ (b) ALP_ms1-2 } & CJt020762_F1O7.F_A & GCCTCCCTCGCGCCACCTCCGGTGTATCAAACTTCAA \\
\hline & CJt020762_F1O7.R & ATTCGCCCTTTCCAAATGTTAGC \\
\hline \multirow[t]{4}{*}{ (c) ALP_ms1 } & CJt020762_ms1-1_F & GCTATAGACTGCACCGACCC \\
\hline & CJt020762_ms1-1_R & AGCCCAGAAAATCGTCCCTG \\
\hline & CJt020762_ms1-2_F & GAATCCACCGCCACGACTAT \\
\hline & CJt020762_ms1-2_R & TGAACTCTGTTTCCATGGCA \\
\hline \multirow[t]{2}{*}{ (d) ASP_ms1-1 } & CJt020762_mt-224F_C.f & CTGTGACTCACTGGCCACAGT $\underline{\mathbf{A} A C}$ \\
\hline & Cjt020762common.r & AGAGAGTGATGGTTTGATTAATGGGAAA \\
\hline \multirow[t]{2}{*}{ (e) ASP_ms1-1_wt } & CJt020762_wt-227F_A.f & GTGACTCACTGGCCACAGTCAT $\underline{A} A A$ \\
\hline & Cjt020762common.r & AGAGAGTGATGGTTTGATTAATGGGAAA \\
\hline \multirow[t]{4}{*}{ (f) LAMP_ms1-1 } & 4D-1_FIP & ACGATGGGGTCGGTGCAGTCTAGCGGTAGCAGAAAGTGTGAT \\
\hline & 4D-1_BIP-3C & ACGAGATCAGCCAAGCTTTCCAACCCTGCGTGGGTㄷG \\
\hline & 4D-1_F3 & GCGGCAATTGTGAGAGCATT \\
\hline & 4D-1_B3 & GAAAATCGTCCCTGGAGACG \\
\hline \multirow[t]{4}{*}{ (g) LAMP_ms1-1_wt } & MS1-190727_FIP-2A & T杰TTGATGACTGTGGCCAGTGAAGATCAGCCAAGCTTTCCAT \\
\hline & MS1-190727_BIP & GGTGCTTGTGCGAGCTCGTCGGAGCGAGAGAGTGATGGTT \\
\hline & MS1-190727_F3 & ATCGTGAGCCTCTCACCA \\
\hline & MS1-190727_B3 & GGTCAAGTTCACGCGGATA \\
\hline \multirow[t]{4}{*}{ (h) LAMP_ms1-2 } & 30D-1-FIP-3T & TGIAGTGATCCCCAAAATAGCCGTTAGCATTGCTGGAGCC \\
\hline & 30D-1-BIP & TGAAGTTTGATACACCGGAGGTTTCTGCTAAATATAACTTTGAACTCTG \\
\hline & $30 \mathrm{D}-1-\mathrm{F} 3$ & TGATTCGCCCTTTCCAAAT \\
\hline & 30D-1-B3 & AGACAACAGCAATTCATTCA \\
\hline
\end{tabular}

a Bold and underlined fonts indicate artificial mismatch introduced to increase specificity

microsatellite forward and reverse primer, $0.2 \mu \mathrm{M}$ of each for both ASP forward and reverse primer (Table 1). The reaction was initially heat-denatured for $15 \mathrm{~min}$ at $95^{\circ} \mathrm{C}$, followed by 38 cycles of $94{ }^{\circ} \mathrm{C}$ for $15 \mathrm{~s}, 63{ }^{\circ} \mathrm{C}$ for $45 \mathrm{~s}$, and $72{ }^{\circ} \mathrm{C}$ for $15 \mathrm{~s}$, using a GeneAmp 9700 PCR System (Applied Biosystems). The PCR products were separated by $2 \%$ agarose gel electrophoresis, and stained with ethidium bromide.

Primer sets for LAMP reactions were designed by PrimerExplorer V5 software (https://primerexplorer.jp/e/ index.html) with wild and mutant type target sequences based on 'Fukushima1' with default parameter setting. Design option "specific" was selected, which allowed us to design allele specific LAMP primers. To increase the specificity of LAMP reactions and discriminate allelic types, an artificial mismatch was introduced at the $3^{\prime}$ or $5^{\prime}$ position of the allele specific primer (the bold and underlined character of the primer sequence in Table 1). LAMP reactions were set up in $25 \mu \mathrm{L}$ of mixture using a DNA amplification kit (Eiken Chemical Co., Ltd.) according to the manufacture's instruction. They were incubated at 63 or $65^{\circ} \mathrm{C}$ for $120 \mathrm{~min}$, and deactivated at $80{ }^{\circ} \mathrm{C}$ for $5 \mathrm{~min}$ or $95^{\circ} \mathrm{C}$ for $2 \mathrm{~min}$. Fluorescent detection reagent (Eiken) was used to visually check the amplified products. These reactions were carried out by GeneAmp 9700 PCR System (Applied Biosystems) or real-time turbidimeter, LoopampEXIA (Eiken).

\section{Results}

The characteristics of PCR based markers are listed in Table 1. Separation of PCR products on the capillary sequencer clearly showed the length difference (in 4-bp between $m s-1$ and others and 30-bp between $m s 1-2$ and others). The difference in length enabled genotype identifications (Table 2 and Additional file 3). Moreover, for Ms1 and ms1-2 alleles, separation on the $2 \%$ agarose gels was attained. Products from heterozygous individual (Ms1/ms1-2) showed three bands indicating heteroduplex formation (Additional file 3). A figure describing the ALP and ASP in different genotypes for MS1 in a blind test trial is provided in Additional file 5.

Allele specific PCR amplified the intended products which allowed the differentiation of the presence or absence of the specific bands on agarose gels (Additional file 3). Under the PCR conditions described in the present study, we observed weak bands of positive control 
Table 2 Expected and observed results of PCR and LAMP diagnostic marker for MS1 in Cryptomeria japonica

\begin{tabular}{|c|c|c|c|c|c|c|}
\hline \multirow[t]{2}{*}{ Maker ID } & \multicolumn{3}{|c|}{ Expected size $(b p)^{\# 1}$ or presence/absence $( \pm)$ of products } & \multicolumn{3}{|c|}{$\begin{array}{l}\text { Observed size (bp) or presence/absence }( \pm) \\
\text { of products }\end{array}$} \\
\hline & Ms1 (wild allele) & $\begin{array}{l}\text { ms1-1 (4-bp } \\
\text { deletion) }\end{array}$ & $\begin{array}{l}\text { ms1-2 (30-bp } \\
\text { deletion) }\end{array}$ & Ms1 (wild allele) & $\begin{array}{l}\text { ms1-1 (4-bp } \\
\text { deletion) }\end{array}$ & $\begin{array}{l}\text { ms1-2 } \\
\text { (30-bp } \\
\text { deletion) }\end{array}$ \\
\hline ALP_ms1-1 & 165 & 161 & 165 & 162 & 158 & 162 \\
\hline ALP_ms1-2 & 146 & 146 & 116 & 141 & 141 & 112 \\
\hline ALP_ms1 & $172 / 288^{\# 2}$ & 168 & 258 & $169 / 286^{\# 2}$ & 165 & 255 \\
\hline ASP_ms1-1 & - & 103 & - & - & + & - \\
\hline ASP_ms1-1_wt & 105 & - & 105 & + & - & + \\
\hline LAMP_ms1-1 & - & + & - & - & + & - \\
\hline LAMP_ms1-1_wt & + & - & + & + & - & + \\
\hline LAMP_ms1-2 & - & - & + & $+^{\# 3}$ & $++^{\# 3}$ & + \\
\hline
\end{tabular}

(SSR marker: CS1364) for cases where the target allele (wild or mutant allele) was present. PCR reaction mainly amplified the target with shorter PCR products. Similarly, for cases where the target alleles were absent, we observed a strong single band of the positive control, this effectively suppressed the unspecific amplification from the mismatched target.

The LAMP primer sets were first designed with complete template-primer matching for each target allele. When possible, loop primers were also tested to speed up the LAMP reaction. Although inclusion of loop primers shortened the reaction time, they often caused falsepositives. Due to these false positives, we used primers with a single artificial mismatch without loop primers. We selected the best allele specific primers (FIP: forward internal primer or BIP: backward internal primer) which showed the fastest amplification (Additional file 6).

\section{Discussion}

We have shown that the mutant alleles for MALE STERILITY 1 (MS1) can be detected in different ways and provided experimental options depending on available laboratory resources. A multiplex PCR reaction can be constructed to simultaneously detect the mutant alleles (ms1-1 and ms1-2). Moreover, multiplex PCR primer sets, including microsatellite markers, will be useful to manage breeding materials for male sterility. These sets enable the clonal identification of each sample. Using the allele specific primer, we could locate the mutant allele among large genetic resources. Additionally, primers that amplify wild type alleles could be useful in mapping families or breeding materials, where genotyping is necessary.
In field forest stations without PCR machines LAMP reactions are convenient. As far as we know, this is the first report to use LAMP for variant detection in coniferous species with a large genome $(10.8 \mathrm{Gbp}$ for $C$. japonica [13]). Our effort mainly focused on the detection of a 4-bp deletion by LAMP because this variant is widespread in our country [5]. In addition, it is hard to separate a 4-bp difference on agarose gel electrophoresis, while a 30-bp difference can be easily separated on $2 \%$ agarose gels (Additional file 3). The LAMP methods for ms1-1 are therefore more requested than those for $m s 1-2$. For LAMP, as for allele specific PCR, the use of artificial mismatch (ARMS-LAMP [14]) increased the specificity, suppressed the amplification from non-target alleles, and increased the speed of amplification for the target allele. However, complete suppression of non-target alleles was difficult (Additional file 3 (h) LAMP_ms1-2). The use of PNA (peptide nucleic acid) [15] to block the alternative allele and to increase the specificity (PNA-LAMP) is an avenue for further study to better refine this method (Additional file 7).

\section{Limitations}

- Multiplex PCR may need optimization, depending on markers (such as microsatellites) combined and PCR machines used.

- LAMP assays may be further optimized by using other primer combinations or applying other methods, such as PNA-LAMP [15]. Sensitivity and specificity of LAMP assay has not been determined, and using both positive and negative controls is necessary to cross-validate the assay. Because we have 
no homozygous individuals with $m s 1-2$ allele and we did not construct plasmid harboring the allele, the LAMP assay to detect wild type allele without a 30-bp deletion is not reported.

- The reactions are not tested for crude DNA, for which further optimization may be needed.

\section{Supplementary information}

Supplementary information accompanies this paper at https://doi. org/10.1186/s13104-020-05296-8.

Additional file 1: Table S1. Summary of the sequencing analysis for 83 individuals for CJt020762. Number of individual trees $(N)$, length of the nucleotide sequence (bp), number of SNPs (nSNP), number of INDELS (nINDEL), number of haplotypes $(n H)$, observed $\left(H_{0}\right)$ and expected heterozygosity $\left(H_{\mathrm{E}}\right)$. $H_{\mathrm{E}}$ was calculated by using GenAlEx 6.5 software.

Additional file 2: Table S2. Buffer composition used for DNA extraction from Cryptomeria japonica. a extraction buffer l, b wash buffer, and $\mathbf{c}$ $2 \times$ CTAB buffer

Additional file 3: Figure S1. Reaction manual and representative results for diagnostic markers. The composition of reaction mixture, thermal conditions, and amplification results for each marker. Marker ID is the same as in Table 1 and 2.

Additional file 4: Table S3. Microsatellite markers tested in multiplex PCR with the diagnostic ASP markers for MS1. Maker ID, fluorescent dye, accession number, SSR motif, expected PCR product size (bp), forward primer sequence, reverse primer sequence, and reference information.

Additional file 5: Figure S2. Blind test trial for (a) ASP_ms1-1, (b) ASP_ ms1-1_wt and (c) ALP_ms1-2. Twenty-three samples were blind-tested for consistency between the assay and expected genotypes based on sequencing analysis.

Additional file 6: Figure S3. Turbidity graph for LAMP assay with ms 1-1 specific BIP primers using 'Shindai3' (a: ms 1-1/ms 1-1) and 'Ooi-7' (b: Ms 1/ms 1-2) DNA template. The $x$-axis indicates time in minutes and the $\mathrm{y}$-axis indicates turbidity.

Additional file 7: Figure S4. PNA-LAMP assay blind test trial for (a) LAMP_ms1-1, (b) LAMP_ms1-1_wt. Twenty-three samples were blindtested for consistency between the assay and expected genotypes based on a sequencing analysis. The detailed protocol is available upon request to the corresponding author.

\section{Abbreviations}

ALP: Amplified length polymorphism; ARMS: Amplification refractory mutation system; ASP: Allele specific PCR; BIP: Backward inner primer; bp: Base pair; DDBJ: DNA Data Bank of Japan; DNA: Deoxyribonucleic acid; FIP: Forward inner primer; Gbp: Giga base pair; LAMP: Loop-mediated isothermal amplification; PCR: Polymerase chain reaction; PNA: Peptide nucleic acid; RNA: Ribonucleic acid.

\section{Acknowledgements}

We thank Eiken Chemical Co., Ltd. for lending us the LoopampEXIA turbidimeter, Nozomi Ohmiya for a part of the laboratory experiments, and two anonymous reviewers and the Editor for their helpful comments. The manuscript was checked by Enago for correct grammar and spelling.

\section{Authors' contributions}

$\mathrm{YH}$ carried out the experiments. SU carried out the experiments and wrote the manuscript. FJW identified the male sterile gene (MS1). AM, KU, TUI performed a part of the experiments. YM was awarded the funding, provided Cryptomeria japonica samples, and performed a part of the experiments. TB, KY, and SS produced genomic sequencing data for C. japonica. TF and MK assembled the genomic sequences. TH provided C. japonica samples. All authors read and approved the final manuscript.

\section{Funding}

This work was supported by grants from the Project of the NARO Bio-oriented Technology Research Advancement Institution (Research program on development of innovative technology (No.28013BC)).

\section{Availability of data and materials}

The DNA sequences of CJ020762 ms1-1 in 'Fukushima1', Ms1 in 'Ajigasawa20' and ms $1-2$ in 'Ooi-7' have been deposited in the DNA Data Bank of Japan (DDBJ) with accession numbers: LC536580, LC538204, and LC538205, respectively (They are available with the following URL: http://getentry.ddbj.nig.ac.jp/ getentry/na/xxxxxxxx/, where xxxxxxxx indicates each accession number). The datasets generated during and/or analyzed during the current study are available from the corresponding author on request.

\section{Ethics approval and consent to participate}

Not applicable.

\section{Consent for publication}

Not applicable.

\section{Competing interests}

YH, SU, FJW, AM, TUI, KU, YM, MK, TF, SS, KY and TB have a patent application.

\section{Author details}

1 Forestry and Forest Products Research Institute, Forest Research and Management Organization, Tsukuba, Ibaraki, Japan. ${ }^{2}$ Graduate School of Science and Technology, Niigata University, Niigata, Japan. ${ }^{3}$ Graduate School of Frontier Sciences, The University of Tokyo, Kashiwa, Chiba, Japan. ${ }^{4}$ National Institute for Basic Biology, Okazaki, Aichi, Japan. ${ }^{5}$ Shizuoka Prefectural Research Institute of Agriculture and Forestry, Hamamatsu, Shizuoka, Japan.

Received: 16 May 2020 Accepted: 17 September 2020

Published online: 29 September 2020

\section{References}

1. Baba K, Nakae K. Epidemiological national survey of nasal allergy 2008 (compared with 1998) in otolaryngologists and their family members (in Japanese). Progress Med. 2008;28:2001-12.

2. Taira H. Utilization and prospect of Cryptomeria japonica male sterility (in Japanese with English abstract). Forest Tree Breeding. 2004;213:8-11.

3. Wei FJ, Ueno S, Ujino-Ihara T, Saito M, Tsumura Y, Higuchi Y, et al. Inspecting abundantly expressed genes in male strobili in sugi (Cryptomeria japonica D. Don) via a highly accurate cDNA assembly. BioRxiv. 2020:2020.04.21.054320.

4. Hasegawa Y, Ueno S, Wei F-J, Matsumoto A, Uchiyama K, Ujino-Ihara $\mathrm{T}$, et al. Identification and genetic diversity analysis of a male-sterile gene MS1 in Japanese cedar (Cryptomeria japonica D. Don). BioRxiv. 2020:2020.05.09.085464.

5. Hasegawa Y, Ueno S, Matsumoto A, Ujino-Ihara T, Uchiyama K, Totsuka S, et al. Fine mapping of the male-sterile genes (MS1, MS2, MS3, and MS4) and development of SNP markers for marker-assisted selection in Japanese cedar (Cryptomeria japonica D. Don). PloS ONE. 2018. 13(11):e0206695. Epub 2018/11/16.

6. Notomi T, Okayama H, Masubuchi H, Yonekawa T, Watanabe K, Amino N, et al. Loop-mediated isothermal amplification of DNA. Nucleic Acids Res. 2000;28(12):63 Epub 2000/06/28.

7. Murray MG, Thompson WF. Rapid isolation of high molecular weight plant DNA. Nucleic Acids Res. 1980;8(19):4321-5 Epub 1980/10/10.

8. Untergasser A, Nijveen H, Rao X, Bisseling T, Geurts R, Leunissen JA. Primer3Plus, an enhanced web interface to Primer3. Nucleic Acids Res. 2007:35:W71-4 Epub 2007/05/09.

9. Rozen S, Skaletsky H. Primer3 on the WWW for general users and for biologist programmers. Methods Mol Biol. 2000;132:365-86 Epub 1999/11/05

10. Blacket MJ, Robin C, Good RT, Lee SF, Miller AD. Universal primers for fluorescent labelling of PCR fragments-an efficient and 
cost-effective approach to genotyping by fluorescence. Mol Ecol Resour. 2012;12(3):456-63 Epub 2012/01/25.

11. Hayashi K, Hashimoto N, Daigen M, Ashikawa I. Development of PCR-based SNP markers for rice blast resistance genes at the Piz locus Theoretical Applied Genetics. 2004;108(7):1212-20.

12. Liu J, Huang S, Sun M, Liu S, Liu Y, Wang W, et al. An improved allelespecific PCR primer design method for SNP marker analysis and its application. Plant Method. 2012;8(1):34.

13. Hizume M, Kondo T, Shibata F, Ishizuka R. Flow Cytometric Determination of Genome Size in the Taxodiaceae, Cupressaceae sensu stricto and Sciadopityaceae. Cytologia: Int J Cytol. 2001;66(3):307-11.

14. Ikeda S, Takabe K, Inagaki M, Funakoshi N, Suzuki K. Detection of gene point mutation in paraffin sections using in situ loop-mediated isothermal amplification. Pathol Int. 2007;57(9):594-9.
15. Sakai J, Maeda T, Tarumoto N, Misawa K, Tamura S, Imai K, et al. A novel detection procedure for mutations in the $23 \mathrm{~S}$ rRNA gene of Mycoplasma pneumoniae with peptide nucleic acid-mediated loop-mediated isothermal amplification assay. J Microbiol Methods. 2017;141:90-6 Epub 2017/08/16.

\section{Publisher's Note}

Springer Nature remains neutral with regard to jurisdictional claims in published maps and institutional affiliations.
Ready to submit your research? Choose BMC and benefit from:

- fast, convenient online submission

- thorough peer review by experienced researchers in your field

- rapid publication on acceptance

- support for research data, including large and complex data types

- gold Open Access which fosters wider collaboration and increased citations

- maximum visibility for your research: over $100 \mathrm{M}$ website views per year

At BMC, research is always in progress.

Learn more biomedcentral.com/submissions 